\title{
Atrial Fibrillation and Dementia
}

\author{
Norbert Guettler, ${ }^{1,2}$ Kim Rajappan ${ }^{3}$ and Edward Nicol ${ }^{4}$ \\ 1. Internal Medicine and Cardiology, Air Force Centre of Aerospace Medicine, Fuerstenfeldbruck, Germany; 2. Central Military Hospital, \\ Koblenz, Germany; 3. Cardiac Department, John Radcliffe Hospital, Oxford University Hospitals NHS Foundation Trust, Oxford, UK; \\ 4. Department of Cardiology, Royal Brompton Hospital, London, UK.
}

$\mathrm{T}$ here is evidence from multiple trials that atrial fibrillation (AF) is associated with cognitive impairment, cognitive decline and dementia. This is true for vascular dementia as well as Alzheimer's disease, with both types of dementia sharing important cardiovascular risk factors. Postulated mechanisms for the development of cognitive decline and dementia in patients with AF are multifactorial and include ischaemic stroke, silent stroke secondary to cerebral microinfarcts, cerebral haemorrhage and chronic cerebral hypoperfusion. Based on several observational studies, it can be expected that anticoagulation with vitamin $\mathrm{K}$ antagonists as well as direct oral anticoagulants may reduce the risk of cognitive decline and dementia in patients with AF. This, however, needs to be proven by randomised trials. Rhythm control by cardioversion or catheter ablation for AF may also reduce the risk of cognitive decline and dementia significantly according to observational studies. Prospective randomised trials to prove the benefit of rhythm control would require a long follow-up in many thousands of patients, and would therefore be challenging to conduct.

\section{Keywords}

Atrial fibrillation, dementia, cognitive decline, cognitive impairment, vascular dementia, Alzheimer's disease, anticoagulation, catheter ablation

Disclosures: Norbert Guettler, Kim Rajappan and Edward Nicol have no financial or non-financial relationships or activities to declare in relation to this article.

Review Process: Double-blind peer review.

Compliance with Ethics: This article involves a review of the literature and did not involve any studies with human or animal subjects performed by any of the authors.

Authorship: The named authors meet the International Committee of Medical Journal Editors (ICMJE) criteria for authorship of this manuscript, take responsibility for the integrity of the work as a whole, and have given final approval for the version to be published.

Access: This article is freely accessible at touchCARDIO.com (c) Touch Medical Media 2020.

Received: 19 April 2020

Accepted: 28 April 2020

Published Online: 22 June 2020

Citation: European Journal of Arrhythmia \& Electrophysiology. 2020;6(1):10-6

Corresponding Author: Norbert Guettler, Air Force Centre of Aerospace Medicine, Strasse der Luftwaffe 322 82256 Fuerstenfeldbruck, Germany. E: guettlern@aol.com

Support: No funding was received for

the publication of this article.
Atrial fibrillation (AF) is one of the most common arrhythmias. It affected 33.5 million people worldwide in 2010, a number that is expected to double by 2050. ${ }^{1} \mathrm{AF}$ prevalence increases with age, and approximately $25 \%$ of individuals aged 40 years or older will develop AF during their lifetime. ${ }^{2,3}$ Irrespective of age, AF incidence also increases with diabetes and hypertension. ${ }^{4}$ The relationship between AF and cerebrovascular events (such as cerebrovascular accident or stroke and transient ischaemic attack), and the increased risk of developing cognitive impairment and dementia, in these patients are well described. ${ }^{1,5-7}$ Recent data suggest that AF may be associated with dementia independent of cerebrovascular events. Possible mechanisms include silent cerebral ischaemia caused by cerebral hypoperfusion and cerebral microhaemorrhage. ${ }^{8}$ Global cerebral hypoperfusion and transient variability in perfusion in the distal cerebral circulation are caused in AF by R-R interval variability and loss of atrial systole. This results in arteriolar hypotension, capillary hypertension and microvascular dysfunction. ${ }^{9}$ A recent computational study suggests a rate-dependent impact of AF on cerebral haemodynamics. Higher ventricular rates relate to a progressive increase in critical cerebral events (hypoperfusion and hypertensive events) at the distal cerebral circle. ${ }^{10}$

Vascular dementia and Alzheimer's disease, the most important degenerative dementia, are the most common types of dementia. On post-mortem findings, Alzheimer's disease is characterised by neurodegenerative changes in the brain, with amyloid depositions and neurofibrillary tangles. There is increasing evidence that stroke and cardiovascular disease are important risk factors for both vascular dementia and Alzheimer's disease. ${ }^{11-15}$ Preclinical findings of cerebrovascular disease, such as increased intima-media thickness of the carotid arteries, white matter lesions and lacunar infarcts in the brain have all been found to be associated with Alzheimer's disease. ${ }^{16-18}$ Additionally, conventional vascular risk factors such as hypertension, diabetes mellitus and smoking have all been noted to be associated with an increased risk of Alzheimer's disease. Similarities in the underlying pathophysiology of vascular dementia and Alzheimer's disease suggest that treatment of cardiovascular disease and associated vascular risk factors may potentially prevent or slow the progression of a significant proportion of Alzheimer cases, as no other effective treatment is available.

Study results indicate that AF probably increases the risk of both vascular dementia and Alzheimer's disease. The relationship to dementia is probably stronger when AF starts in middle age and with a longer duration of $A F^{19,20}$ This article outlines the current evidence regarding the relationship between AF and dementia; possible mechanisms of disease; and potential treatment options for $A F$, that may decrease the risk of, or progression of, cognitive decline and dementia.

\section{Trials investigating the association of atrial fibrillation and dementia}

Evidence of the association between AF and dementia is based on prospective and retrospective observational trials, cross-sectional studies, systematic reviews and meta-analyses. 
Table 1: Important prospective and retrospective studies on the association between atrial fibrillation and cognitive decline, cognitive impairment or dementia

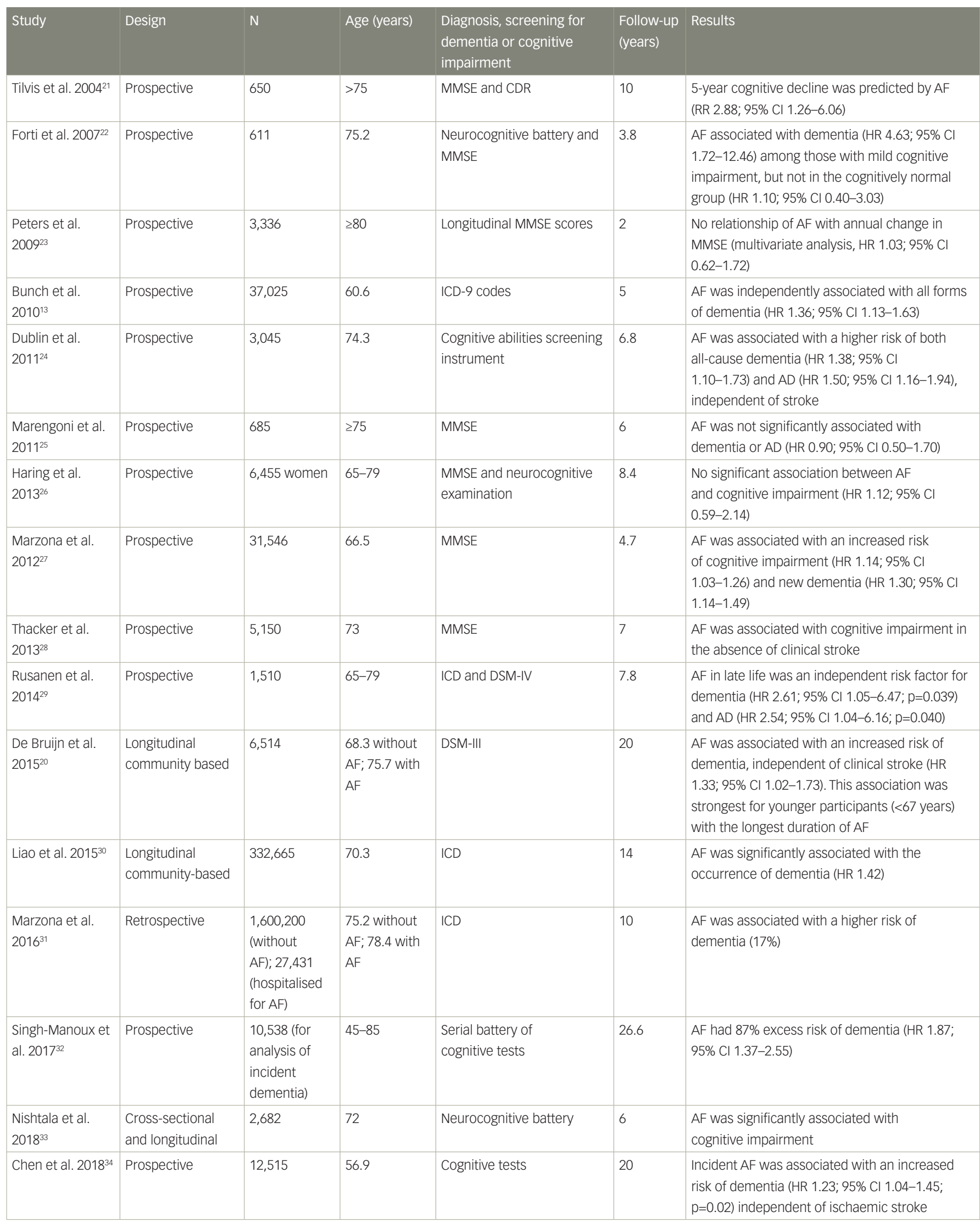


Table 2: Important cross-sectional studies on the association between atrial fibrillation and cognitive decline, cognitive impairment or dementia

\begin{tabular}{|c|c|c|c|c|}
\hline Study & N & Age (years) & $\begin{array}{l}\text { Diagnosis, screening for } \\
\text { dementia or cognitive } \\
\text { impairment }\end{array}$ & Results \\
\hline Ott et al. $1997^{19}$ & 6,584 (195 with AF) & 69.2 & MMSE score $<26$ & $\begin{array}{l}\text { Positive associations of AF with both dementia (OR 2.3; 95\% Cl } \\
\text { 1.4-3.7) and cognitive impairment (OR 1.7; 95\% Cl 1.2-2.5) }\end{array}$ \\
\hline Jozwiak et al. $2006^{35}$ & 2,314 (hospitalised) & 76 & MMSE score $<24$ & Positive associations of AF with cognitive impairment (OR 1.56) \\
\hline Elias et al. $2006^{36}$ & $\begin{array}{l}\text { 1,011 men } \\
(59 \text { with AF) }\end{array}$ & 61 & Neuropsychological testing & $\begin{array}{l}\text { Significantly lower mean levels of cognitive performance in men } \\
\text { with AF }\end{array}$ \\
\hline $\begin{array}{l}\text { Kawabata-Yoshihara et } \\
\text { al. } 2012^{37}\end{array}$ & 1,524 (37 with AF) & $>65$ & DSM-IV criteria & $\begin{array}{l}\text { No independent association between AF and dementia (OR for } \\
\text { dementia in participants with AF was 2.8; } 95 \% \mathrm{Cl} 1.0-8.1 ; \mathrm{p}=0.06 \text { ) }\end{array}$ \\
\hline Di Nisio et al. $2015^{38}$ & 784 (103 with AF) & 77.5 & DSM-IV & $\begin{array}{l}\text { AF was associated with } 2.0 \text {-fold increase in vascular dementia }(21.4 \% \\
\text { versus } 10.7 \% ; p=0.024) \text { and } 1.72 \text {-fold increase in } A D(12.6 \% \text { versus } \\
7.3 \% ; p=0.046)\end{array}$ \\
\hline Alonso et al. $2017^{39}$ & 6,432 (611 with AF) & $\begin{array}{l}76 \text { (no AF); } \\
79 \text { (with AF) }\end{array}$ & Neurocognitive battery & $\begin{array}{l}\text { AF was associated with higher prevalence of dementia (OR 2.25; } \\
95 \% \mathrm{Cl} 1.64-3.10) \text { and mild cognitive impairment (OR 1.28; } 95 \% \mathrm{Cl} \\
\text { 1.04-1.56) }\end{array}$ \\
\hline
\end{tabular}

$A D=$ Alzheimer's disease; $A F=$ atrial fibrillation; $C l=$ confidence interval; DSM = Diagnostic and Statistical Manual of Mental Disorders; MMSE = Mini-Mental State Examination; $N=$ number of patients; $O R=$ odds ratio.

Table 3: Systematic reviews and meta-analyses evaluating the association between atrial fibrillation and cognitive decline, cognitive impairment or dementia

\begin{tabular}{|c|c|c|c|}
\hline Review/meta-analysis & Number of studies & Number of participants & Results \\
\hline Kwok et al. $2011^{40}$ & $\begin{array}{l}15 \text { (prospective, } \\
14 \text { included in } \\
\text { meta-analysis) }\end{array}$ & 46,637 & $\begin{array}{l}\text { Association between AF and increased incidence of dementia in patients with stroke } \\
\text { (OR 2.0; } 95 \% \mathrm{Cl} 1.4-2.7 ; \mathrm{p}<0.0001 \text { ); for broader populations borderline significance } \\
\text { (7 studies, OR 1.6; 95\% } \mathrm{Cl} 1.0-2.7 ; \mathrm{p}=0.05 \text { ) }\end{array}$ \\
\hline Santangeli et al. $2012^{41}$ & $\begin{array}{l}8 \text { (prospective } \\
\text { observational) }\end{array}$ & $77,668(11,700$ with AF) & $\begin{array}{l}\text { AF was independently associated with increased risk of dementia (HR } 1.42 ; 95 \% \mathrm{Cl} \\
1.17-1.72 ; p<0.001)\end{array}$ \\
\hline $\begin{array}{l}\text { Udompanich et al. } \\
2013^{42}\end{array}$ & $\begin{array}{l}8 \text { ( } 3 \text { cross-sectional, } \\
2 \text { case-control, } \\
3 \text { prospective) }\end{array}$ & $\begin{array}{l}\text { Range across } \\
\text { 11 studies: } \\
\text { 74-37,025 }\end{array}$ & $\begin{array}{l}\text { Association between AF and cognitive impairment and/or dementia (cross-sectional } \\
\text { studies: } 1.7 \text {-fold [95\% } \mathrm{Cl} 1.2-2.5] \text { to } 3.3 \text {-fold }[95 \% \mathrm{Cl} 1.6-6.5] \text { increased risk of cognitive } \\
\text { impairment, } 2.3 \text {-fold [95\% C: } 1.4-3.7 \text { ] increased risk of dementia for AF patients) }\end{array}$ \\
\hline $\begin{array}{l}\text { Kalantarian et al. } \\
2013^{43}\end{array}$ & $\begin{array}{l}21 \text { (prospective and } \\
\text { non-prospective) }\end{array}$ & 89,907 & $\begin{array}{l}\text { AF was associated with a higher risk for cognitive impairment and dementia, with or } \\
\text { without a history of clinical stroke (cognitive impairment: RR 1.34; 95\% Cl 1.13-1.58; } \\
\text { dementia: RR 1.38; } 95 \% \mathrm{Cl} 1.22-1.56 \text { ) }\end{array}$ \\
\hline Islam et al. $2019^{44}$ & 16 (observational) & $2,415,356$ & $\begin{array}{l}\text { AF was associated with an increased risk of dementia (HR 1.36; } 95 \% \mathrm{Cl} 1.23-1.51 \text {; } \\
p<0.0001 \text { ) }\end{array}$ \\
\hline
\end{tabular}

$A F=$ atrial fibrillation; $\mathrm{Cl}=$ confidence interval; $H R=$ hazard ratio; $O R=$ odds ratio; $R R=$ relative risk.

A selection of the most important observational studies is summarised in Table 1, 13,20-34 with cross-sectional studies in Table 2. ${ }^{19,35-39}$ For the diagnosis of dementia, Mini-Mental State Examination (MMSE) and cognitive tests were performed in most studies.

Several meta-analyses and systematic reviews have investigated the association between $\mathrm{AF}$ and dementia. A selection of those is listed in Table $3 .{ }^{40-45} \mathrm{~A}$ systematic review of three cross-sectional, two case-control and three prospective studies, conducted by Udompanich et al. in 2013, found an association between cognitive impairment and AF. In the cross-sectional studies, patients with AF had a 1.7-fold to 3.3-fold increased risk of cognitive impairment, and a 2.3-fold increased risk of dementia, compared with patients in sinus rhythm. ${ }^{42}$ Three meta-analyses with prospective and cross-sectional studies have demonstrated an increased risk of dementia in those with AF, with or without a history of stroke. ${ }^{40,41,43}$ Individuals with a history of stroke were at greater risk for dementia and cognitive decline and a strong association between AF and dementia was demonstrated in patients under 75 years of age. A more recent meta-analysis of 16 observational studies (almost 2.5 million individuals) demonstrated patients with AF had a greater incidence dementia than those without. ${ }^{44}$

In another meta-analysis of 11 prospective cohort studies covering 112,876 patients, AF was independently associated with dementia incidence. ${ }^{45} \mathrm{~A}$ meta-analysis including five prospective observational studies with a total of 61,008 patients and a median follow-up of 12.5 years also indicates an increased risk of dementia in patients with AF.' According to this meta-analysis, stroke/transient ischaemic attack-independent contribution of AF to dementia is more impactful than stroke/transient ischaemic attack-dependent effect. The association of AF with cognitive impairment and dementia was also evaluated in a meta-analysis including 21 studies. $^{43}$ In this cohort, there was a 
Figure 1: Assumed relationship between atrial fibrillation, cognitive decline and dementia via different mechanisms

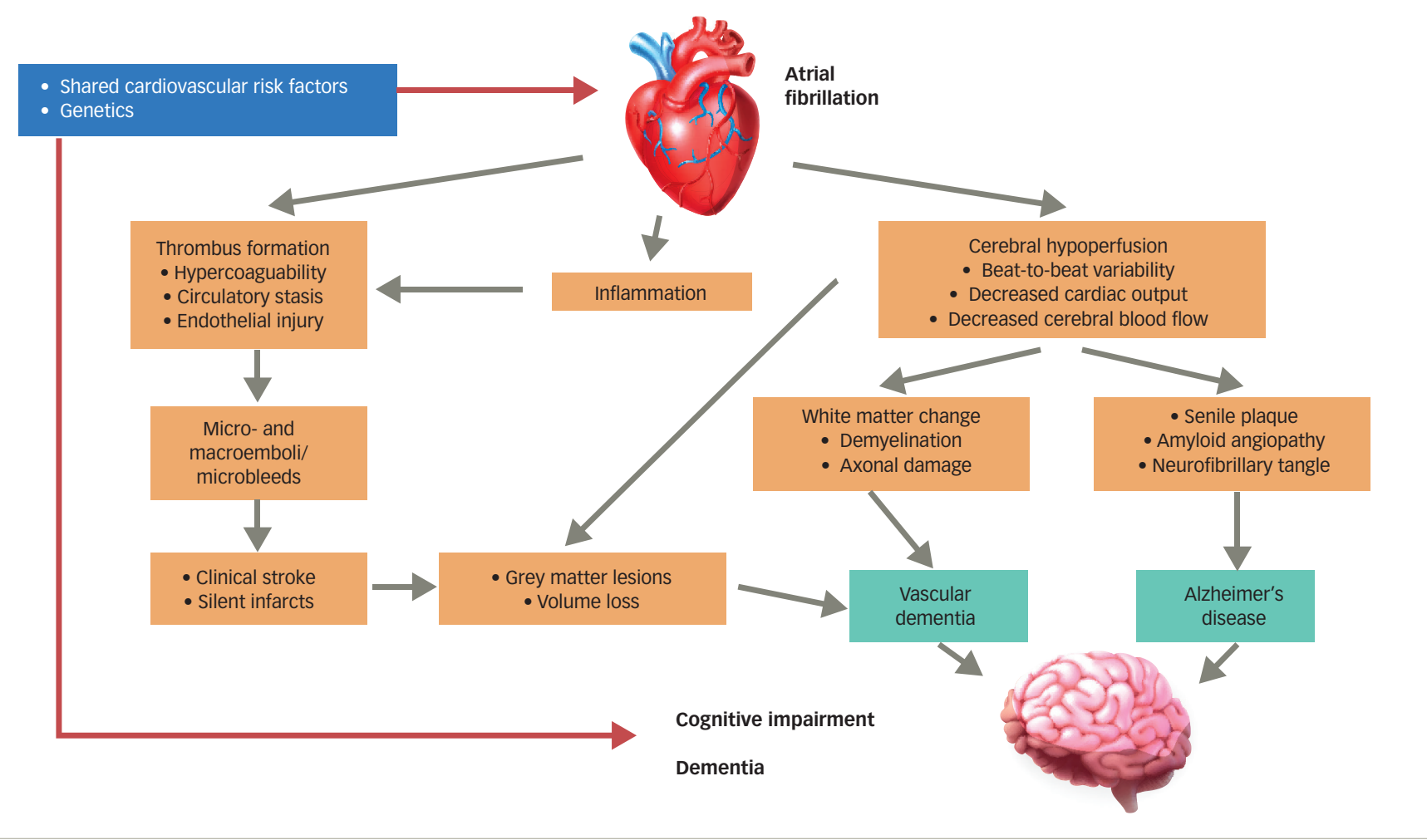

significant association between AF and an increased risk of cognitive impairment independent of a history of stroke. The risk of dementia was also significantly increased.

Thus, there is scientific evidence from very large meta-analyses that suggest $A F$ is an independent risk factor for dementia in patients with normal baseline cognitive function not suffering from acute stroke. Screening for dementia in patients with $\mathrm{AF}$, and including dementia as an independent outcome in large AF trials, is required to confirm this association in prospective and clinical practice..$^{45}$

\section{Possible mechanisms underlying the association between atrial fibrillation and dementia}

It is assumed that AF accelerates neuropathological processes that cause and coexist with dementia, such as the development of Lewy bodies, neurofibrillary tangles and hippocampal sclerosis. ${ }^{46}$ The mechanisms as to how AF leads to dementia are not fully understood, however it is postulated that the main mechanisms are probably cerebral hypoperfusion caused by beat-to-beat variation in $\mathrm{AF}$, with reduced cardiac output, silent cerebral ischaemia (caused by thromboembolism because of a hypercoagulable state), circulatory stasis, endothelial injury and upregulation of inflammatory processes. .7.48 $^{47}$

Cerebral hypoperfusion aggravates white matter change leading to demyelination and axonal damage, and subsequent memory

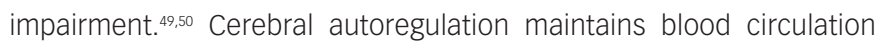
even if cardiac output decreases, but may deteriorate in patients with long-term AF..$^{51}$ Long-term cerebral hypoperfusion induces senile plaque formation and amyloid angiopathy through $\beta$ - and $\gamma$-secretases. These generate and aggregate $\beta$-amyloid peptide in the brain, which is thought to be responsible for neuronal death and Alzheimer's disease. ${ }^{52}$ cerebral amyloid angiopathy is mainly caused by amyloid $\beta 42\left(A \beta_{42}\right)$, with $A \beta_{40}$ triggering a reduction in blood supply within the brain and driving further $A \beta$ production secondary to dysfunction of the vascular smooth muscle..$^{53}$ Decreased cerebral blood flow can be measured by single-photon emission tomography (SPECT) with 99mtechnetium-ethyl cysteinate dimer, with potential prognostic value in patients with both AF and dementia. ${ }^{54}$

Recent data suggest an increased prevalence of cerebral microbleeds in patients with $A F$, which can also play a role in the pathogenesis of cognitive decline and dementia. 2.55 The most vulnerable area for the development of cerebral microbleeds is the hippocampus, which is often affected in patients with Alzheimer's disease and $\mathrm{AF}^{56}$

AF is also associated with a proinflammatory state, but the exact relationship between $\mathrm{AF}$-induced systemic inflammation and dementia requires further investigation. ${ }^{2} \mathrm{~A}$ proinflammatory state is implicated in the genesis and perpetuation of $A F$, facilitating thrombus formation and leading to stroke or silent ischaemia. Inflammatory markers identified in patients with $A F$ and dementia include C-reactive protein, interleukin (IL)-2, IL-6, IL-8, and tumour necrosis factor alpha. ${ }^{12}$ The role of inflammatory and infectious processes serving as links between AF and Alzheimer's disease has recently been analysed. ${ }^{57}$

Genetic analysis reveals that AF-related gene PITX2, the gene for the homeobox transcription factor, is significantly associated with dementia. This genetic factor could explain that the relative risk of dementia is paradoxically higher in younger patients with $A F^{47.48} \mathrm{~A}$ study of 37,025 patients without dementia and a follow-up of at least 5 years showed the highest relative risk (RR) of developing Alzheimer's dementia among those with AF and younger than 70 years of age. ${ }^{13} \mathrm{~A}$ higher risk of dementia in younger patients with $\mathrm{AF}(<67$ years of age) was also seen in a study analysing participants of the Rotterdam Study. ${ }^{20}$ 
Table 4: Ongoing clinical trials on atrial fibrillation and cognitive impairment, cognitive decline and dementia

\begin{tabular}{|c|c|c|c|}
\hline Study (official title) & $\begin{array}{l}\text { ClinicalTrials.gov } \\
\text { Identifier }\end{array}$ & Study type & Recruitment status \\
\hline $\begin{array}{l}\text { Randomized Clinical Trial for the Prevention of Cognitive Impairment in Atrial Fibrillation } \\
\text { Patients Treated With Dabigatran or Warfarin (GIRAF) }\end{array}$ & NCT01994265 & Interventional & Active, not recruiting \\
\hline $\begin{array}{l}\text { Mild Cognitive Impairment (MCI) in Patients With Atrial Fibrillation (AF), Trajectories of the } \\
\text { Progression of } \mathrm{MCl} \text { and Factors Associated With the Progression (DIAL-F) }\end{array}$ & NCT01816308 & $\begin{array}{l}\text { Observational } \\
\text { (patient registry) }\end{array}$ & Recruiting \\
\hline $\begin{array}{l}\text { Impact of Anticoagulation Therapy on the Cognitive Decline and Dementia in Patients With } \\
\text { Non-Valvular Atrial Fibrillation (CAF Trial) }\end{array}$ & NCT03061006 & Interventional & Recruiting \\
\hline $\begin{array}{l}\text { Overall and MRI-based Impact of Percutaneous Left Atrial Appendage Closure on the } \\
\text { Cognitive Decline and Dementia in Patients With Atrial Fibrillation (PLUG Dementia Trial and } \\
\text { MRI PLUG Dementia Sub-Study) }\end{array}$ & NCT03091855 & Observational & Recruiting \\
\hline $\begin{array}{l}\text { Randomized Trial of Apixaban vs Dose Adjusted Warfarin in Reducing Rate of Cognitive } \\
\text { Function Decline, Silent Cerebral Infarcts and Cerebral Microbleeds in Non-valvular Atrial } \\
\text { Fibrillation Patients With CHA2DS2-VaSc Score = } 2 \text { (ARISTA) }\end{array}$ & NCT03839355 & Interventional & Recruiting \\
\hline Swiss Atrial Fibrillation Cohort Study (SWISS-AF) & NCT02105844 & Observational & Active, not recruiting \\
\hline Atrial Fibrillation and the Risk for Neurological Complications & NCT00357227 & Observational & Unknown \\
\hline Acute Cognitive Changes During Atrial Fibrillation Episodes (AFCOG) & NCT04033510 & Observational & Recruiting \\
\hline $\begin{array}{l}\text { AntiCoagulants and COGnition (ACCOG Trial): a Single-blind Randomized Controlled Trial } \\
\text { Comparing the Neurocognitive Effects of Rivaroxaban Versus Vitamin K Antagonist }\end{array}$ & NCT04073316 & Interventional & Not yet recruiting \\
\hline $\begin{array}{l}\text { Non-Interventional Study on Effectiveness of Elxaban Tab. in Patients With Non-valvular } \\
\text { Atrial Fibrillation }\end{array}$ & NCT04125641 & $\begin{array}{l}\text { Observational } \\
\text { (patient registry) }\end{array}$ & Recruiting \\
\hline $\begin{array}{l}\text { Comparison of Brain Perfusion in Rhythm Control and Rate Control of Persistent Atrial } \\
\text { Fibrillation: Prospective Randomized Trial }\end{array}$ & NCT02633774 & Interventional & Recruiting \\
\hline $\begin{array}{l}\text { Blinded Randomized Trial of Anticoagulation to Prevent Ischemic Stroke and Neurocognitive } \\
\text { Impairment in AF (BRAIN-AF) }\end{array}$ & NCT02387229 & $\begin{array}{l}\text { Interventional } \\
\text { (clinical trial) }\end{array}$ & Recruiting \\
\hline
\end{tabular}

This shows that the association between AF and dementia is not only caused by age-dependent pathological conditions as common risk factors. The currently assumed relationship between AF, cognitive decline and dementia is summarised in Figure 1.

\section{Treatment options for atrial fibrillation decreasing the risk of cognitive decline and dementia}

Treatment options for AF are anticoagulation, if indicated, rate control and rhythm control. There is some evidence in the literature that therapeutic options that control rhythm and risk of thromboembolic disease could also have positive effects on cognitive decline and dementia.

\section{Anticoagulation}

Observational trials, such as the Olmsted county population-based study, suggest that anticoagulation of patients with AF with warfarin is associated with reduced cognitive decline. ${ }^{2}$ However, possible confounders limit confidence in ascribing a cause-effect relationship. The importance of an optimal time in therapeutic range (TTR) was emphasised in this trial. A total of 2,800 patients with AF without dementia were enrolled. Incident dementia was diagnosed in 357 patients (12.8\%) over a mean follow-up of 5 years. After adjusting for confounders, warfarin therapy was associated with a reduced incidence of dementia (hazard ratio [HR] 0.80; 95\% confidence interval $[\mathrm{Cl}]$ 0.64-0.99). However, only those in the two highest quartiles of TTR were associated with a lower risk of dementia. The importance of TTR for a positive effect of anticoagulation with vitamin $\mathrm{K}$ antagonists was also reported in two other studies. ${ }^{58,59}$
A systematic review of 19 studies analysed the association between cognitive impairment and anticoagulation. ${ }^{60}$ The pooled odds ratio (OR) suggested no association with incident dementia, when comparing anticoagulation with antiplatelet therapy (two studies, OR 1.23; 95\% Cl 0.80-1.91) or no treatment (three studies, OR 0.89; 95\% Cl 0.47-1.69). Thus, this review did not show definitive evidence of cognitive benefit or harm from anticoagulation. Direct oral anticoagulants (DOACS) have also been evaluated with regards to their impact on new-onset dementia and compared with warfarin. In a propensity-matched analysis, the risk of developing stroke, transient ischaemic attack or dementia was $43 \%$ lower in patients treated with DOACs compared with warfarin; but this difference was not statistically significant (HR 0.57; 95\% Cl 0.17-1.97; $p=0.38$ ). ${ }^{61}$

A Swedish retrospective registry study conducted between 2006 and 2014, including 444,106 patients with AF with no previous diagnosis of dementia, investigated the possible effect of anticoagulation on the incidence of dementia. ${ }^{2}$ Propensity score matching, falsification endpoints, intention-to-treat, and on-treatment analyses were used. Patients without prior stroke and on anticoagulation treatment had a $29 \%$ lower risk of dementia than patients without anticoagulation (HR 0.71; 95\% Cl 0.68-074). Comparison between DOACs and warfarin showed no significant difference.

In a Danish nationwide cohort study including 33,617 patients with AF with a mean follow-up of 3.4 years, no clinically meaningful difference in dementia development between users of DOACs and warfarin was found. ${ }^{63}$ Relative to warfarin users, dementia rates were non-significantly lower among DOAC users aged 60-69 years 
(HR 0.92; 95\% Cl 0.48-1.72) and DOAC users aged 70-79 years (HR 0.86; $95 \% \mathrm{Cl}$ 0.68-1.09), whereas DOACs were associated with significantly higher dementia rates in patients aged $\geq 80$ (HR 1.31; 95\% Cl 1.07-1.59). According to the authors, the latter may relate to residual confounding from selective prescribing and unobserved comorbidities.

In summary, there is indirect evidence that effective anticoagulation in patients with AF reduces the risk of cognitive impairment and dementia. Large prospective clinical trials on this subject are needed.

\section{Rhythm control}

Cardioversion, or AF ablation, may result in sinus rhythm and improve cardiac output and cerebral perfusion. The impact of these treatment options on dementia has been investigated in several studies. In the Intermountain AF study, 4,212 consecutive patients with AF who underwent AF ablation were compared with 16,848 age- and sex-matched control subjects with AF without ablation and 16,848 age- and sex-matched individuals without AF. ${ }^{64}$ Follow-up was $>3$ years and Alzheimer's disease occurred in $0.2 \%$ of the patients who underwent AF ablation, $0.9 \%$ of the patients with AF but no ablation and in $0.5 \%$ of the patients without AF $(p<0.0001)$. Other forms of dementia also appear to be significantly reduced by AF ablation; in a recent study, the risk of dementia and hospitalisation was studied in 787 patients with AF who received catheter ablation, and their propensity scores were matched to 787 patients with AF not receiving ablation, and 770 patients without AF. Over $9.0( \pm 2.6)$ years of follow-up, 139 dementia events and $732 \mathrm{AF}$-related hospitalisations occurred. In those patients with AF who underwent ablation, the incidence of dementia was lower than in the group without ablation (adjusted HR 0.44, p=0.005). AF-related hospitalisations were also lower in the ablation group (adjusted HR 0.72 , $p<0.05)$. The reduction of dementia risk was especially clear in older patients aged $>65$ years with AF ablation, compared with those without AF ablation (adjusted HR 0.46, $\mathrm{p}=0.03$ ). ${ }^{65}$ According to the MACPAF (Mesh Ablator versus Cryoballoon Pulmonary vein Ablation of Symptomatic Paroxysmal Atrial Fibrillation) study, AF burden had no significant impact on cognitive performance 6 months after AF ablation. ${ }^{66}$

Further ongoing clinical trials on the association between AF, cognitive impairment, cognitive decline and dementia are summarised in Table 4.

\section{Conclusion}

AF can be regarded as an independent cardiovascular risk factor for the development of cognitive decline and dementia. Several recent studies suggest an association between AF, cognitive impairment, cognitive decline and dementia, in those both with and without a history of stroke. AF increases the risk of vascular dementia as well as Alzheimer's disease. Both types of dementia and AF share the same risk factors, including hypertension, heart failure, diabetes, dyslipidaemia, age, obesity and physical inactivity. These risk factors, alone or in combination, can lead to silent strokes and microbleeds, as well as chronic cerebral hypoperfusion, which are more common in patients with AF than in patients in sinus rhythm. The association between AF and dementia is strongest in patients $<65$ years of age.

Anticoagulation, either with vitamin $\mathrm{K}$ antagonists or DOACs, has been proven to be effective in preventing strokes in AF and there is emerging evidence that anticoagulation in patients with AF could also be effective to reduce cognitive decline even in those without a history of stroke. This, however, still needs to be proven in ongoing and future clinical trials. $\square$
1. Saglietto A, Matta A, Gaita F, et al. Stroke-independent contribution of atrial fibrillation to dementia: a meta-analysis Open Heart. 2019;6:e000984.

2. Madhavan $M$, Graff-Radford J, Piccini JP, et al. Cognitive dysfunction in atrial fibrillation. Nat Rev Cardiol. 2018;15:744-56

3. Myserlis PG, Malli A, Kalaitzoglou DK, et al. Atrial fibrillation and cognitive function in patients with heart failure: a systematic review and meta-analysis. Heart Fail Rev. 2017;22:1-11.

4. Watanabe $\mathrm{H}$, Tanabe $\mathrm{N}$, Watanabe $\mathrm{T}$, et al. Metabolic syndrome and risk of development of atrial fibrillation: the Niigata preventive medicine study. Circulation. 2008;117:1255-60.

5. Bunch TJ, Galenko O, Graves KG, et al. Atrial fibrillation and dementia: exploring the association, defining risks and improving outcomes. Arrhythm Electrophysiol Rev. 2019;8:8-12.

6. Bunch TJ, Bair TL, Crandall BG, et al. Stroke and dementia risk in patients with and without atrial fibrillation and carotid arterial disease. Heart Rhythm. 2020;17:20-6

7. Ktawczyk M, Fridman S, Cheng Y, et al. Atrial fibrillation diagnosed after stroke and dementia risk: cohort study of first-ever ischaemic stroke patients aged 65 or older. Europace. 2019;21:1793-801

8. Hui DS, Morley JE, Mikolajczak PC, et al. Atrial fibrillation: a major risk factor for cognitive decline. Am Heart J. 2015;169:448-56

9. Anselmino M, Scarsoglio S, Saglietto A, et al. Transient cerebral hypoperfusion and hypertensive events during atrial fibrillation: a plausible mechanism for cognitive impairment. Sci Rep. 2016;6:28635.

10. Saglietto $A$, Scarsoglio S, Ridolfi L, et al. Higher ventricular rate during atrial fibrillation relates to increased cerebral rate during atrial fibrillation relates to increased cerebral
hypoperfusions and hypertensive events. Sci Rep. 2019;9:3779.

hypoperfusions and hypertensive events. Sci Rep. 2019, 1. Santos CY, Snyder PJ, WuWC, et al. Pathophysiologic
relationship between Alzheimer's disease, cerebrovascula disease, and cardiovascular risk: a review and synthesis. Alzheimers Dement (Amst). 2017;7:69-87.

2. Dietzel J, Haeusler KG, Endres M. Does atrial fibrillation cause cognitive decline and dementia? Europace. 2018;20:408-19.

13. Bunch $T J$, Weiss JP, Crandall $B G$, et al. Atrial fibrillation is independently associated with senile, vascular, and Alzheimer's dementia. Heart Rhythm. 2010:7:433-7.

14. Kelleher RJ, Soiza RL. Evidence of endothelial dysfunction in the development of Alzheimer's disease: is Alzheimer's a vascular disorder? Am I Cardiovasc Dis. 2013;3:197-226.

15. Qiu C, Winblad B, Marengoni A, et al. Heart failure and risk of dementia and Alzheimer disease: a population-based cohort dementia and Alzheimer disease: a popul

16. Newman AB, Fitzpatrick AL, Lopez O. Dementia and Alzheimer's disease incidence in relationship to cardiovascular disease in the Cardiovascular Health Study cohort. J Am Geriatr SOC 2005;53:1101-7.
17. Wendell $C R$, Waldstein $S R$, Ferrucci L, et al. Carotid atherosclerosis and prospective risk of dementia. Stroke. 2012;43:3319-24

18. Prins ND, van Dijk EJ, den Heijer T, et al. Cerebral white matter lesions and the risk of dementia. Arch Neurol. 2004;61:1531-4.

19. Ott A, Breteler MM, de Bruyne MC, et al. Atrial fibrillation and dementia in a population-based study. The Rotterdam Study. Stroke. 1997;28:316-20.

20. De Bruijn RF, Heeringa J, Wolters FJ, et al. Association between atrial fibrillation and dementia in the general population. JAMA Neurol. 2015;72:1288-94.

21. Tilvis RS, Kähönen-Väre $M H$, Jolkkonen J, et al. Predictors of cognitive decline and mortality of aged people over a 10-year period. J Gerontol A Biol Sci Med Sci. 2004;59:268-74.

22. Forti P, Maioli F, Pisacane N, et al. Atrial fibrillation and risk of dementia in non-demented elderly subjects with and without mild cognitive impairment. Arch Gerontol Geriat without mild cognitive impan

23. Peters $R$, Poulter $R$, Beckett $N$, et al. Cardiovascular and biochemical risk factors for incident dementia in the Hypertension in the Very Elderly Trial. J Hypertens. 2009;27:2055-62.

24. Dublin S, Anderson ML, Haneuse SJ, et al. Atrial fibrillation and risk of dementia: a prospective cohort study. J Am Geriatr Soc 2011;59:1369-75

25. Marengoni A, Qiu C, Winblad B, et al. Atrial fibrillation, stroke and dementia in the very old: a population-based study. Neurobiol Aging. 2011;32:1336-7.

26. Haring B, Leng X, Robinson J, et al. Cardiovascular disease and cognitive decline in postmenopausal women: results from the Women's Health Initiative Memory Study. J Am Heart Assoc. 2013:2:e000369.

27. Marzona I, O'Donnell M, Teo K, et al. Increased risk of cognitive and functional decline in patients with atrial fibrillation: results of the ONTARGET and TRANSCEND studies. CMA. 2012;184:E329-36

28. Thacker EL, MCKnight B, Psaty BM, et al. Atrial fibrillation and cognitive decline: a longitudinal cohort study. Neurology. 2013;81:119-25

29. Rusanen M, Kivipelto M, Levälahti E, et al. Heart diseases and long-term risk of dementia and Alzheimer's disease: a population-based CAIDE study. J Alzheimers Dis. 2014;42:183-91.

30. Liao JN, Chao TF, Liu CJ, et al. Risk and prediction of dementia in patients with atrial fibrillation - a nationwide population-based cohort study. Int J Cardiol. 2015;199:25-30.

31. Marzona I, Baviera M, Vannini T, et al. Risk of dementia and death in patients with atrial fibrillation: a competing risk analysis of a population-based cohort. Int $J$ Cardiol. 2016;220:440-4.
32. Singh-Manoux A, Fayosse A, Sabia S, et al. Atrial fibrillation as a risk factor for cognitive decline and dementia. Eur Heart J. 2017;38:2612-8

33. Nishtala A, Piers RJ, Himali JJ, et al. Atrial fibrillation and cognitive decline in the Framingham heart study. Heart Rhythm. 2018;5:166-72.

34. Chen LY, Norby FL, Gottesman RF, et al. Association of atrial fibrillation with cognitive decline and dementia over 20 years: the ARIC-NCS (Atherosclerosis Risk in Communities Neurocognitive Study). J Am Heart Assoc. 2018;7:e007301.

35. Jozwiak A, Guzik P, Mathew A, et al. Association of atrial fibrillation and focal neurologic deficits with impaired cognitive function in hospitalized patients $>0 \mathrm{O}=65$ years of age. Am J Cardiol. 2006;98:1238-41.

36. Elias MF, Sullivan LM, Elias PK, et al. Atrial fibrillation is associated with lower cognitive performance in the Framingham offspring men. J Stroke Cerebrovasc Dis. 2006;15:214-22

37. Kawabata-Yoshihara LA, Scazufca M, Santos IS, et al. Atrial fibrillation and dementia: results from the Sao Paulo ageing and health study. Arq Bras Cardiol. 2012;99:1108-14.

38. Di Nisio M, Prisciandaro M, Rutjes AW, et al. Dementia in patients with atrial fibrillation and the value of the Hachinski ischemic score. Geriatr Gerontol Int. 2015;15:770-7.

39. Alonso A, Knopman DS, Gottesman RF, et al. Correlates of dementia and mild cognitive impairment in patients with atrial fibrillation: the atherosclerosis risk in communities neurocognitive study (ARIC-NCS). J Am Heart ASSOC. 2017:6:e006014.

40. Kwok CS, Loke YK, Hale R, et al. Atrial fibrillation and incidence of dementia: a systematic review and meta-analysis. Neurology. 2011;76:914-22.

41. Santangeli P, Di Biase $L$, Bai R, et al. Atrial fibrillation and the risk of incident dementia: a meta-analysis. Heart Rhythm. 2012;9:1761-8

42. Udompanich S, Lip GY, Apostolakis S, et al. Atrial fibrillation as a risk factor for cognitive impairment; a semi-systematic review. QJM. 2013;106:795-802.

43. Kalantarian S, Stern TA, Mansour M, et al. Cognitive impairment associated with atrial fibrillation: a meta-analysis. Ann Intern Med. 2013:158:338-46.

44. Islam MM, Poly TN, Walther BA, et al. Association between atrial fibrillation and dementia: a meta-analysis. Front Aging Neurosci. 2019;11:305.

45. Liu DS, Chen J, Jian WM, et al. The association of atrial fibrillation and dementia incidence: a meta-analysis of prospective cohort studies. J Geriatr Cardiol. 2019;16:298-306.

46. Kamel H, Okin PM, Elkind MS, et al. Atrial fibrillation and mechanisms of stroke: time for a new model. Stroke. 2016;47:895-900 
47. Jacobs V, Cutler MJ, Cay JD, et al. Atrial fibrillation and dementia. Trends Cardiovasc Med. 2015;25:44-51.

48. Rivard L, Khairy P. Mechanisms, clinical significance, and prevention of cognitive impairment in patients with atrial frevention of cognitive impairment in patients

49. Shibata M, Ohtani $\mathrm{R}$, Ihara $\mathrm{M}$, et al. White matter lesions and glial activation in a novel mouse model of chronic cerebral hypoperfusion. Stroke. 2004;35:2598-603.

50. Ihara $\mathrm{M}$, Tomimoto $\mathrm{H}$. Lessons from a mouse model characterizing features of vascular cognitive impairment with white matter changes. J Aging Res. 2011;2011:978761.

51. Akinyemi RO, Mukaetova-Ladinska EB, Attems J, et al. Vascular risk factors and neurodegeneration in ageing related dementias: Alzheimer's disease and vascular dementia. Curr Alzheimer Res. 2013;10:642-53.

52. Pluta R, Furmaga-Jabłońska W, Maciejewski R, et al. Brain ischemia activates $\beta$ - and $\gamma$-secretase cleavage of amyloid precursor protein: significance in sporadic Alzheimer's disease. Mol Neurobiol. 2013;47:425-34.

53. Niwa K, Kazama K, Younkin L, et al. Cerebrovascular autoregulation is profoundly impaired in mice overexpressing autoregulation is profoundly impaired in mice overexpressin
amyloid precursor protein. Am I Physiol Heart Circ Physiol. 2002;283:H315-23.
54. Hashimoto H, Nakanishi R, Mizumura S, et al. Prognostic value of ${ }^{99 m} \mathrm{mC}-\mathrm{ECD}$ brain perfusion SPECT in patients with atrial fibrillation and dementia. EJNMMI Res. 2020;10:3

55. Akoudad S, Wolters FJ, Viswanathan A, et al. Association of 政 cerebral microbleeds with cognitive decline and dementia.
JAMA Neurol. 2016:73:934-43.

56. Silva RMFLD, Miranda CM, Liu T, et al. Atrial fibrillation and risk of dementia: epidemiology, mechanisms, and effect of anticoagulation. Front Neurosci. 2019;13:18

57. Martins GL, Duarte RCF, Mukhamedyarov MA, et al. Inflammatory and infectious processes serve as links between atrial fibrillation and Alzheimer's disease. Int J Mol SCi. 2020;21:E3226

58. Wan $Y$, Heneghan C, Perera R, et al. Anticoagulation control and prediction of adverse events in patients with atrial fibrillation: a systematic review. Circ Cardiovasc Qual Outcomes. 2008:1:84-91.

59. Jacobs $\mathrm{V}$, Woller SC, Stevens S, et al. Time outside of therapeutic range in atrial fibrillation patients is associated with long-term risk of dementia. Heart Rhythm. 2014:11:2206-13.

60. Moffitt P L Lane DA, Park $H$, et al. Thromboprophylaxis in atrial fibrillation and association with cognitive decline: systematic review. Age Ageing. 2016;45:767-75.
61. Jacobs V, May HT, Bair TL, et al. Long-term population-based cerebral ischemic event and cognitive outcomes of direct oral anticoagulants compared with warfarin among long-term anticoagulated patients for atrial fibrillation. Am I Cardiol. 2016;118:210-4.

62. Friberg L, Rosenqvist M. Less dementia with oral anticoagulation in atrial fibrillation. Eur Heart J. 2018;39:453-60

63. Søgaard M, Skjøth F, Jensen M, et al. Nonvitamin K antagonist oral anticoagulants versus warfarin in atrial fibrillation patients and risk of dementia: a nationwide propensity-weighted cohort study. J Am Heart ASSOC. 2019;8:e011358.

64. Bunch TJ, Crandall BG, Weiss JP, et al. Patients treated with catheter ablation for atrial fibrillation have long-term rates of death, stroke, and dementia similar to patients without atria fibrillation. J Cardiovasc Electrophysiol. 2011;22:839-45.

65. Hsieh YC, Chen YY, Chien KL, et al. Catheter ablation of atrial fibrillation reduces the risk of dementia and hospitalization during a very long-term follow-up. Int J Cardiol. 2020;304:75-81.

66. Herm J, Schirdewan A, Koch L, et al. Impact of atrial fibrillation burden on cognitive function after left atrial ablation - results burden on cognitive function after left atrial ablation - resul
of the MACPAF study. I Clin Neurosci. 2020:73:168-72. 